\title{
Spatio-Temporal Population Modelling for Enhanced Assessment of Urban Exposure to Flood Risk
}

\author{
Alan Smith • David Martin • Samantha Cockings \\ Received: 23 October 2013 / Accepted: 2 July 2014 / \\ Published online: 1 August 2014 \\ C) The Author(s) 2014. This article is published with open access at Springerlink.com
}

\begin{abstract}
There is a growing need for high resolution spatio-temporal population estimates which allow accurate assessment of population exposure to natural hazards. Current approaches to population estimation are usually limited either by the use of arbitrary administrative boundaries or insufficient resolution in the temporal dimension. The innovative approach proposed here combines the use of a spatio-temporal gridded population model with flood inundation data to estimate time-specific variations in population exposed to natural hazards. The approach is exemplified through an application centred on Southampton (UK) using Environment Agency flood map inundation data. Results demonstrate that large fluctuations occur over time in the population distribution within flood risk zones. Variations in the spatio-temporal distribution of population subgroups are explored. Analysis using GIS indicates a diurnal shift in exposure between fluvial and tidal flooding, particularly attributable to the movement of the working age population. This illustrates the improvements achievable to flood risk management as well as potential application to other natural hazard scenarios both within the UK and globally.
\end{abstract}

Keywords Spatio-temporal modelling · Population surface modelling · Natural hazards · Vulnerability · Urban exposure

\section{Introduction}

Natural hazards are one of the ultimate constraints on human activities (Mitchell 1999) and occur on a variety of time scales from sudden onset events such as earthquakes to gradual processes such as drought. A natural hazard has the potential to develop into a disaster as soon as it poses a risk to humans. Increasing incidence and frequency of natural hazards events during the last century have been attributed to better recording and increased habitation of hazardous areas (Alexander 1993; Tobin and Montz 1997; Hilhorst and Bankoff 2008). Humans are becoming more susceptible to hazards as a

A. Smith $(\bowtie) \cdot$ D. Martin $\cdot$ S. Cockings

Geography and Environment, University of Southampton, Southampton SO17 1BJ, UK

e-mail: Alan.Smith@soton.ac.uk 
consequence of population growth and urbanisation (Huppert and Sparks 2006). In particular, flood losses are increasing in major coastal cities (Hallegatte et al. 2013). Prominent events since 2011 have refocused attention on natural hazards and human vulnerability both in terms of fatalities and economic impacts. By a considerable margin, 2011 was the mostly costly year to date with natural hazards losses totalling US\$380 billion and 27,000 fatalities (Munich Re 2012). The most notable events included the Japanese tsunami and Christchurch earthquake as well as severe flooding in Thailand, Australia and the USA and continued drought in east Africa.

To better understand the effects of natural hazards and develop more robust emergency plans, an improved knowledge of the spatial and temporal distribution of population is required (Bhaduri et al. 2007; Fielding 2007; Aubrecht et al. 2012a; Harper and Mayhew 2012). Calculating the population exposed is not straightforward as both the hazard and population vary over time (McPherson and Brown 2004). Inadequacies in mapping population have been noted for many decades (e.g. Schmitt 1956). Commonly used official population datasets such as census or population registers usually provide only residential 'night-time' population counts. In the United Kingdom (UK) it has been estimated that 5.2 million properties are at risk from flooding (DEFRA 2011), but there is little understanding of the numbers of people at risk. This paper highlights the significant improvements that can be achieved in assessment of population exposure to natural hazards by the integration of innovative spatiotemporal population modelling methods with maps of hazard extents. It demonstrates the importance of high-resolution space- and time-specific population data and illustrates their utility in a UK flood risk case study. The analysis is implemented using the SurfaceBuilder247 software (Martin 2011) and Geographic Information Systems (GIS).

The remainder of the paper is structured as follows. The next section provides an overview of flooding in the UK and the proposed spatio-temporal population modelling approach. The third section describes the source datasets and modelling methodology. Section four introduces the study site used for the combination of flood hazard and spatiotemporal population modelling. This is followed by the results and discussion in sections five and six. The final section presents some conclusions and suggested further work.

\section{Background}

For the first time in human history more people now live in urban than rural areas (United Nations 2008). Rapid urbanisation and the concentration of population in flood prone areas has increased human susceptibility to flood-related hazards. New building and redevelopment in urban areas has increased ground surface sealing and encroachment into low lying land and areas at risk of flooding. A reconsideration of risk management policies is required in order to account for population at varying spatiotemporal scales and reverse the trend of increasing urban flood risk (Zevenbergen et al. 2008). Northern Europe, including the UK, has a long history of severe coastal flooding (Ruocco et al. 2011). Qualitative descriptions of these events and their impacts on local populations are contained within numerous historical records. The most catastrophic sudden onset event to occur in the UK during the last 500 years was the 20 January 1607 flood in the Bristol Channel (Horsburgh and Horritt 2006; RMS 2007) which led to many fatalities in Southwest England and South Wales. The UK continues to have a 
record of significant destructive fluvial (Marsh 2008; 2004), tidal (Baxter 2005) and flash (Bettess 2005; Burt 2005; Murray et al. 2012; Rowe 2004; McGinnigle 2002) flood events.

Prominent flood events over the last decade in the UK and Europe have had a significant impact on legislation and policy. Major natural hazard incidents have been recognised by the UK government as one of the highest priority risks facing the country (HM Government 2010). The Pitt review (Pitt 2008), which was commissioned following substantial UK-wide flooding in June and July 2007, resulted in 92 recommendations. Key recommendations concerning flood risk assessment and management included: calls for local authorities to collate and map the main flood risk management and drainage assets (Recommendation 16); encouragement for individuals to be better prepared and become self-reliant during emergencies allowing the authorities to focus on the people most in need (70); and the impact of flooding on the health and wellbeing of people to be monitored and mitigations put in place to manage these effects (74). Recommendations 70 and 74 illustrate the need for a greater understanding of exposed populations, while recommendation 16 concerns mapping the physical infrastructure. Improved mapping and modelling of both the hazard and the population exposed are required for effective emergency planning and management.

The European Union Floods directive of the European Parliament (OJ 2007) has also had implications for the way flood risk is managed in the UK. Inter-agency and international collaboration remain key components in flood risk management. Member states were to have provided flood hazard and risk maps by 22 December 2013 and flood risk management plans by 22 December 2015 (OJ 2007). The Flood Risk Regulations 2009 implement the requirements of the directive in the UK. The UK Environment Agency is responsible for producing the relevant hazard and risk maps for England and Wales within the specified timescale and lead Local Flood Authorities have been identified to map local flood risk.

The spatial and temporal distributions of population and natural hazards are complex and occur at a range of scales. The population exposed is a key component when defining risk to natural hazards, as is vulnerability of specific population subgroups. Variation in the location and magnitude of vulnerable populations exposed to natural hazards at different times needs to be recognised if emergency planning is to be improved (Cutter and Finch 2008). Lack of data or inadequate sophistication in either, or both, of the spatial and temporal aspects of population estimation have seriously hampered previous efforts to understand such characteristics. Some researchers have quantified population exposure based on properties exposed and average occupancy rates (e.g. Hunter et al. 2008; Hall et al. 2005; Wadey et al. 2012). The methodology presented here extends population exposure estimation into the temporal dimension. The paper is not concerned with the definition and investigation of vulnerability and resilience per se, nor does it attempt to make predictions of perceptions of risk or human behaviour during emergencies, all of which are also important; rather, it demonstrates how enhanced spatio-temporal estimates of population can facilitate the identification of vulnerable populations exposed to natural hazards. Such estimates can then inform improved risk and emergency management plans.

The hazard component also has complex spatio-temporal characteristics, which may be represented by simple static risk maps or dynamic models. In order to make accurate risk assessments, knowledge of the likely onset time, severity, duration and 
geographical extent of a hazard scenario are required. For example, while a storm surge may have a long lead-time a tsunami may not.

The detailed spatial distribution of population is often obscured by the convention of displaying uniform densities in contiguous zones, such as census areas, that cover the entire surface (Martin and Bracken 1993). Similarly, the spatial distribution of natural hazards does not conform to administrative boundaries. Any analysis using geographically aggregated data is prone to the modifiable areal unit problem (MAUP) Openshaw (1984), although the effects of MAUP can be minimised by using data at the finest possible spatial resolution. Dasymetric methods can improve the spatial accuracy of interpolation via the use of ancillary datasets and have been successfully employed in population surface estimation (e.g. Mennis 2003).

Interpolating data onto a grid is a further method which can offer some resilience to the problems associated with irregular zonal representations. Benefits include the inclusion of unpopulated cells; the standard size and shape of individual cells; the invariant nature of the cell boundaries over time and the relative ease of incorporating data from statistical models of physical phenomena. Examples of gridded population models include the $1 \mathrm{~km}$ disaggregated gridded population for Europe (Aubrecht et al. 2012b) and gridded population of the world (CIESIN 2013).

Although gridded population models provide many advantages for estimating population exposure to natural hazards they are still only a static representation of population at a given point in time. The method proposed in this paper offers flexibility and granularity in the temporal dimension while building on the inherent advantages of the gridded model, but a gridded representation is not a pre-requisite for its implementation.

\section{Methods and Data}

The methodology proposed here contains three subcomponents, shown in Fig. 1. Figure 1a covers the spatio-temporal population modelling process, 1b the hazard component and 1c brings these GIS-based datasets together for analysis. Often natural hazard and population models are not linked. The proposed methodology aims to demonstrate the improvements to risk analysis when these subcomponents are more fully integrated.

The spatio-temporal population modelling component (Fig. 1a) is illustrated schematically in Fig. 2, which shows a small area containing three locations a, b and c at two times, $T_{1}$ and $T_{2}$. For each time, the left hand diagram shows population density on the vertical axis and space on the horizontal, while the right hand diagram shows the same population distribution in map view. In this highly simplified example, $\mathrm{T}_{1}$ represents night time, when population is present at locations a and $b$, which are the centroids of residential areas of differing spatial extent, but no population is present at location c which is a workplace, only occupied during the day. In the absence of exact areal extents for every possible population location, it is necessary to employ a distance decay function around points of high information such as population-weighted centroids. We here use the Cressman (1959) distance decay function, established in this context (Martin 1996). $\mathrm{T}_{2}$ represents day time, when lower population densities are present at residential locations $\mathrm{a}$ and $\mathrm{b}$, but the workplace $\mathrm{c}$ displays a high population 


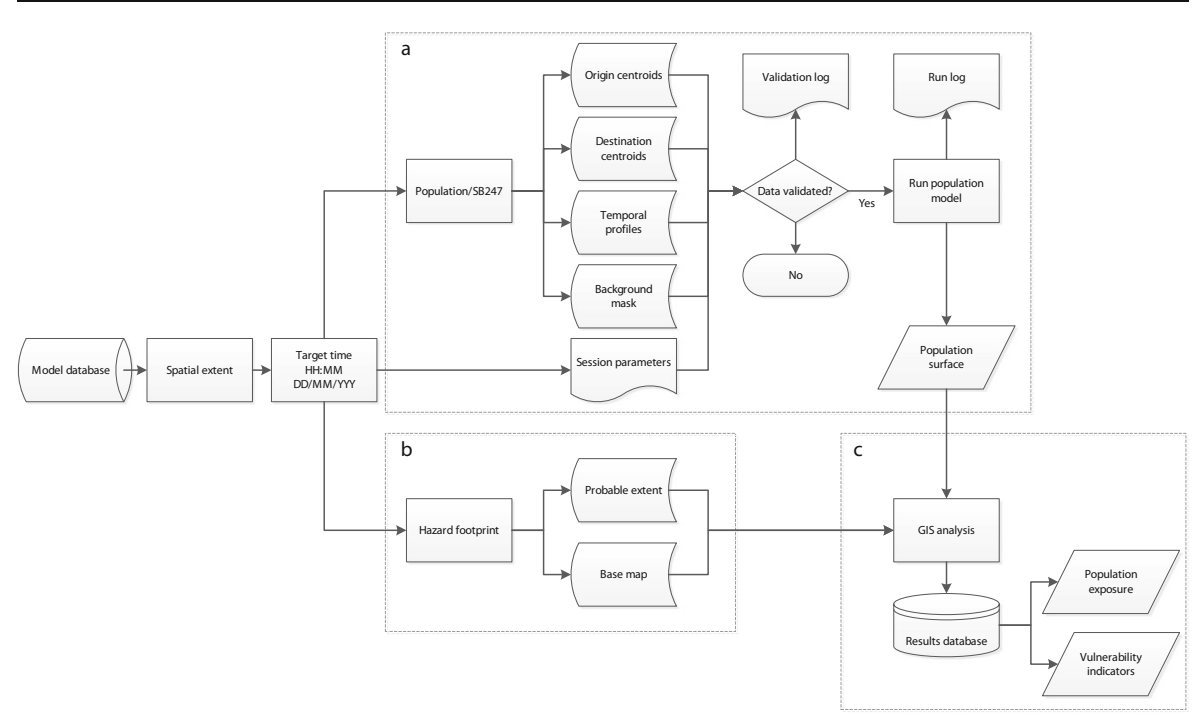

Fig. 1 Overview of analytical operations to assess natural hazard exposure

density over a relatively small spatial extent. Between these times, the study area may have exchanged commuters with neighbouring areas and the total population contained at times $T_{1}$ and $T_{2}$ therefore need not be the same. At either time period, the population present may be aggregated to any relevant mapping units, such as the cells of a regular grid. (Martin 1989, 1996) presented a surface modelling algorithm which mapped population from population-weighted centroid locations onto a regular grid by means of adaptive kernel density estimation, with the local density of centroids determining the spatial extent over which population is spread. In common with most conventional census mapping, this approach effectively reproduced only the night time residential situation shown here at time $\mathrm{T}_{1}$, without any explicit consideration of reference times.
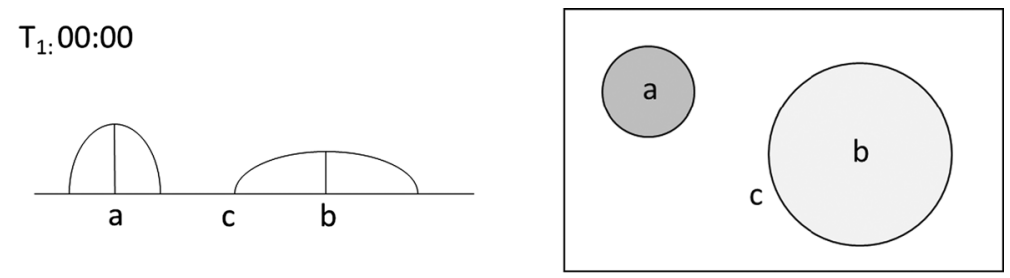

$\mathrm{T}_{2} 12: 00$
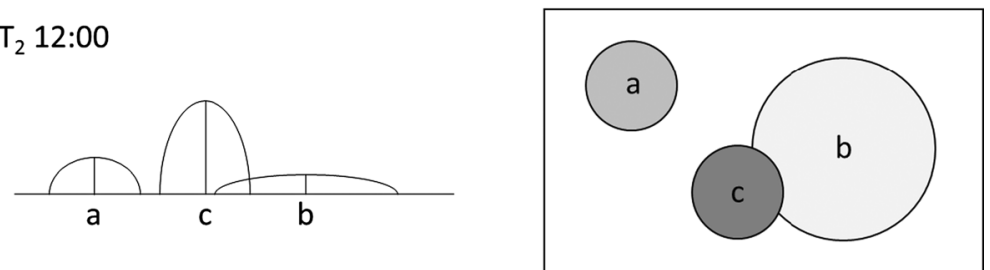

Fig. 2 Schematic of population centroid density represented by vertical density curves (left) and spread (right) at two given times of the day 
In this paper, we employ an extension of this approach using the SurfaceBuilder247 software described in Martin (2011), which is a development of the original model and which uses a time profile of human activity at each centroid rather than a single value. The same algorithm is employed for redistribution of population across space, but is here undertaken with reference to the populations anticipated to be present at each centroid at a specified target time. In the SurfaceBuilder247 implementation, centroids are designated as either origins or destinations. The total population to be modelled is determined by the sum of the populations at the origin centroids within the study area, such as a and $b$ in Fig. 2.

Processing begins with the establishment of a full dataset of origin and destination locations for the chosen study area and a surrounding region to reflect anticipated commuting flows. Detailed file specifications and data field definitions are provided in Martin (2011). Censuses typically provide an accurate and comprehensive small area population count and the smallest spatial units for which detailed census data are available in England and Wales are output areas (OAs), with a mean population size of 300. Population weighted OA centroids from the 2001 census, updated with data from 2006 mid-year estimates, have been used as the origin centroids in this study. It should be noted that the full range of equivalent data from the 2011 census had not been published at the time this research was undertaken.

Secondly, destination centroids represent the range of possible non-residential locations of population. A population capacity is assigned to each destination centroid, such as the number of staff and students at a school or patients and staff at a hospital, obtained from administrative data sources. Any number of destination centroids may be introduced to represent additional locations of human activity which do not contribute to the residential population base. The spatial extents and catchment areas of destinations are specified, which indicate, respectively, the size of the site and the geographical range from which population should be drawn. Thus (for example) a primary school could be represented as a destination location, with a time profile in which all children on the roll are present during the school day, allocated to a small site of extent $100 \mathrm{~m}$ and drawn from a catchment radius of $3 \mathrm{~km}$. A dataset of destination locations was initially collated for the Population $24 / 7$ project, $^{1}$ which includes places of work, education, and health care. The example presented here extends these datasets by building on this original library of potential population locations. It is a feature of the model's structure (Fig. 1a) that users can develop their own datasets, particularly for non-residential locations. Time profiles, the third component in Fig. 1a, have been developed for each destination centroid, based on a range of data sources describing the opening hours of different workplaces and services. The time profile derived from ancillary information provides the proportion of a site's capacity population which is present at any specific time.

The development of retail destinations is provided here as an example of how additional activity types can be added to the Population 24/7 destination datasets. This example serves to exemplify the process of dataset creation and is just one of many destination types that could be represented. Retail was chosen as it is another major activity type which attracts significant non-residential populations and was not explicitly included in the original Population 24/7 estimates. This example uses national time

${ }^{1}$ Population24/7 project details: http://www.esrc.ac.uk/my-esrc/grants/RES-062-23-1811/read 
use survey data to estimate the total number of shopping trips and then allocates these to destinations based on the recorded size of the retail workforce in each area. Equivalent retail data of higher accuracy could be derived from commercial sources as part of a large-scale implementation but were neither available nor necessary for the purposes of this example.

A temporal profile for shopping activity was created as a simple estimate of retail activity (Fig. 3) by analysing episodic diary data from the Time Use Survey (TUS) (Ipsos-RSL, and ONS 2000). Respondents (n: 20,981) kept a coded diary entry for $10 \mathrm{~min}$ intervals throughout the day. Analysis of the retail components within the TUS data identified average shopping durations and travel times. These were both used to inform travel to catchment parameters and length of retail trips by individuals. In line with expectations, it can be observed that people shop for longer on a Saturday and travel further. These data produced estimates of the total numbers of shoppers and time spent shopping.

The number of retail employees at the Lower Layer Super Output Area (LSOA) geography was derived from the Annual Business Inquiry (ABI) dataset (ONS 2006a). The size of the retail workforce was then used to allocate total retail activity from the TUS to approximate retail locations based on business postcodes (ONS 2006b). LSOAs are the next smallest statistical units in England and Wales after census OAs and typically contain 1,500 residents. They are the smallest units for which ABI data are available. Postcodes are georeferenced locations designed to facilitate the delivery of mail and businesses receiving large amounts of mail will generally be allocated their own postcode. It is acknowledged that large user postcodes will also include non-retail offices and business locations, but this simple approach nevertheless permits the reallocation of large population volumes from residential to retail locations during shopping hours. The total shopping time from the time use survey and retail employees from ABI were combined to estimate the number of shopping hours supported by each retail employee, taking account of the demand pattern for each day and the variable duration of shopping activities. Estimated population numbers engaged in retail activity are thus allocated to each business postcode by time of day.

A background raster GIS data layer constrains the population distribution, delineating areas of uninhabitable space such as the sea and other water bodies, and incorporating the principal road network weighted according to UK Department for Transport

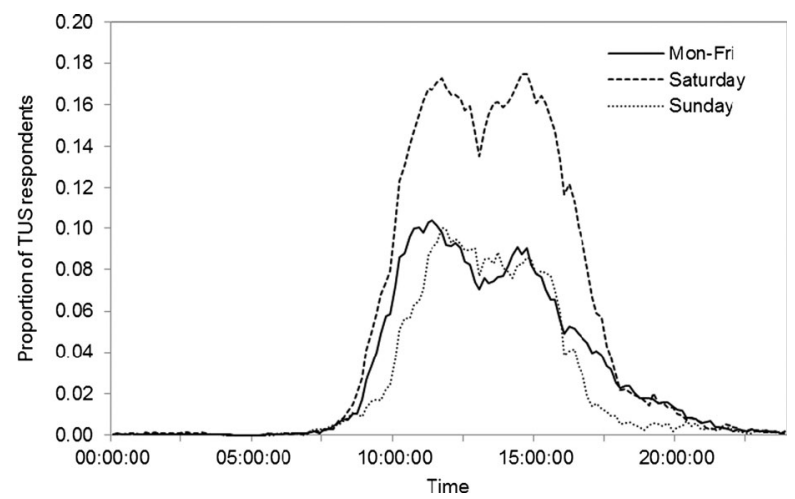

Fig. 3 Retail temporal profiles according to TUS (2000) respondents who engaged in retail activity 
traffic count data (DfT 2013). Average annual daily flows for each DfT survey point by vehicle type are redistributed according to time of day, day of week and road category (motorway and principal urban/rural roads) according to the National Transport Model (DfT 2005). This reproduces observed temporal variations in traffic flow throughout the week. The traffic count by vehicle type is subsequently converted to a population estimate for each rasterized road cell based on specific vehicle occupancy rates (DfT 2009). The population estimated to be travelling at any target time is assigned onto this weighted background layer.

For this study, population data are modelled onto a regular spatial grid with $200 \mathrm{~m}$ cell size which is appropriate to the resolution of the available input data sources. The Population 24/7 methodology has been designed to allow subgroups of the population to be modelled separately. In the application described here, modelling has been undertaken for seven age groups: pre-school aged children, primary school age, secondary school age, further education students, higher education students, remaining working age population and those retired. These subgroups have distinctive temporal patterns such as typical school hours and term times. The modelling technique is volume preserving. Population counts derived from the origin locations are redistributed across origin and destination locations and the background layer, ensuring that the overall population total is preserved within each modelled age group. Known in- and out- flows to the system, such as long-distance commuting, can be incorporated into the model but have not been applied in this case study.

Figure $1 \mathrm{~b}$ relates to the natural hazard modelling component. In the example application presented here (Environment Agency flood map (for July 2012)) (EA 2012) are employed to delineate the spatial footprint of the flood hazard. The flood map is the result of probabilistic and scenario-led hydraulic modelling. The most likely scenario under the 'zone three' extent (high probability) (EA 2012) has been utilised. Its spatial extent is shown in Fig. 4. This scenario models inundation caused by fluvial and tidal flooding with a $1 \%$ and $0.5 \%$ annual probability of occurrence respectively. The modelled population surfaces (Fig. 1a) and flood extents (Fig. 1b) have then been integrated using GIS (Fig. 1c).

The modelling framework allows exploration of variation in population exposure to flooding over a range of temporal scales e.g. hourly, daily or seasonally, broken down by different subgroups of the population. In this paper, the populations for a typical working weekday and a Sunday during school term time for 2007 are modelled and population exposure estimates within the potential flood extent are calculated for twohourly intervals between 08:00 and 20:00. A static baseline exposure estimate using rasterised 2001 census data has also been calculated for comparative analysis.

\section{Example Application: Study Area}

A $25 \times 25 \mathrm{~km}$ study area centred on Southampton Water (Fig. 4) has been chosen for an example flood risk application. The Solent separates the Isle of Wight from southern England and provides a natural deep water channel for large shipping vessels. The region's industrial and shipping success has been attributed to the complex tidal system, which produces a double high-tide, but the combination of the region's topography, location and tidal system also has the potential to dramatically increase the flood risk 


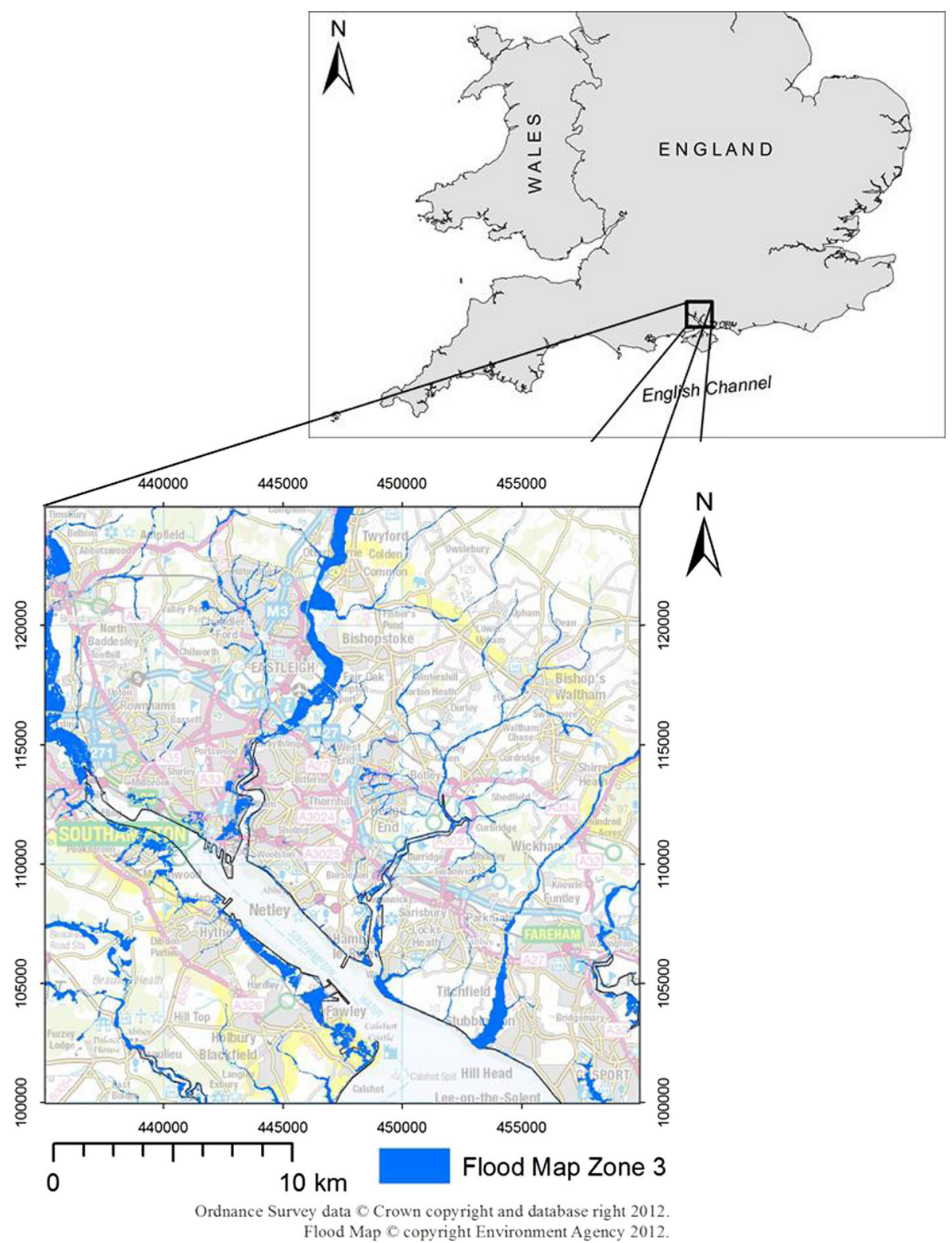

Fig. 4 Application study area centred on Southampton (UK) showing potential flood inundation

within the area. Southampton Water is a narrow funnel-like channel leading from the Solent to the Port of Southampton, vulnerable to storm surges driven by low pressure systems which can lead to increases in sea level of up to $1 \mathrm{~m}$ (Ruocco et al. 2011) or north sea surges that propagate through the English Channel (Wadey et al. 2012). When combined with high spring tides these events pose a heightened flood risk and exert pressure on existing defences. Historical record analysis by Ruocco et al. (2011) discovered up to 20 flood events in Southampton since 1935. Approximately 24,000 
properties are considered to be within the tidal flood plain of a 1 in 200 year flood event in the Solent region (NFDC 2009). Within the study area, approximately $78 \mathrm{~km}^{2}$ is at risk of tidal or fluvial flood inundations under the zone three scenario (shown in blue in Fig. 4).

The study area and its low lying urban areas contain major coastal transportation links, population centres and commercial and military ports. These activities have contrasting spatio-temporal patterns, making the area of particular interest for spatiotemporal population modelling. A major employer is the Port of Southampton which is the country's busiest cruise ship terminal and second largest container dock (ABP 2013). On a busy summer weekend, the central area population may be swelled for example by tens of thousands of passengers and crew on-board cruise ships visiting the port (not modelled here) and by visitors to the region's major shopping centre which has an average weekly footfall of c. 300,000 (WestQuay 2011).

Estimates of potential exposure to the hazard are calculated for various subgroups of the population for a range of time slices. Students in higher education are recognised as a key spatially mobile section of the population with strategic importance (King and Ruiz-Gelices 2003). The predominant local authority (Southampton) modelled in the study area for this paper had a 2011 residential population count of 236,882, including $32,111(13.6 \%)$ full-time students in higher education. The two universities within the study area (University of Southampton and Southampton Solent University) had a combined 2011/12 student population of 38,885 (HESA 2012). Students account for a significant proportion of population flows and seasonal variation. Notably, two evacuations of the student population in Aberystwyth, UK, during severe coastal flood events in January 2014 (Gevertz 2014) has demonstrated their vulnerability and strategic importance, even if they are generally considered to be a relatively resilient sector of society.

\section{Results}

Figure 5a shows total population for rasterised 2001 census OAs and the population modelled in $200 \mathrm{~m}$ grid cells for three different times of day (Fig. $5 \mathrm{~b}$ to d). There is a stark difference between the conventional static census based population model in Fig. $5 \mathrm{a}$ and the gridded representations in $5 \mathrm{~b}-5 \mathrm{~d}$ which much more accurately indicate the higher central densities and extensive unpopulated areas, even in this relatively urbanized region. A large daily variation in population occurs. During the working day (Fig. 5c), population becomes highly concentrated in specific areas such as the city centre and in local clusters such as schools and colleges, as employees and students travel to, and temporally remain at, places of work and study. Population also increases in other non-residential areas of the city associated with activities such as retail and transport. The 08:00 model differs from the 20:00 model with more people in the transportation network at 08:00 - mostly on their way to work or school (Fig. 5b and d).

There are spatial (Fig. 5) and temporal (Fig. 6) variations in populations potentially exposed to flood hazards during the day. Analysis of the results suggests that the total population exposed peaks towards the end of the typical working day (Fig. 6). Differentiating the flood risk components (Fig. 6) reveals a further interesting phenomenon within the Southampton study area: throughout the day, exposure to fluvial flood risk 

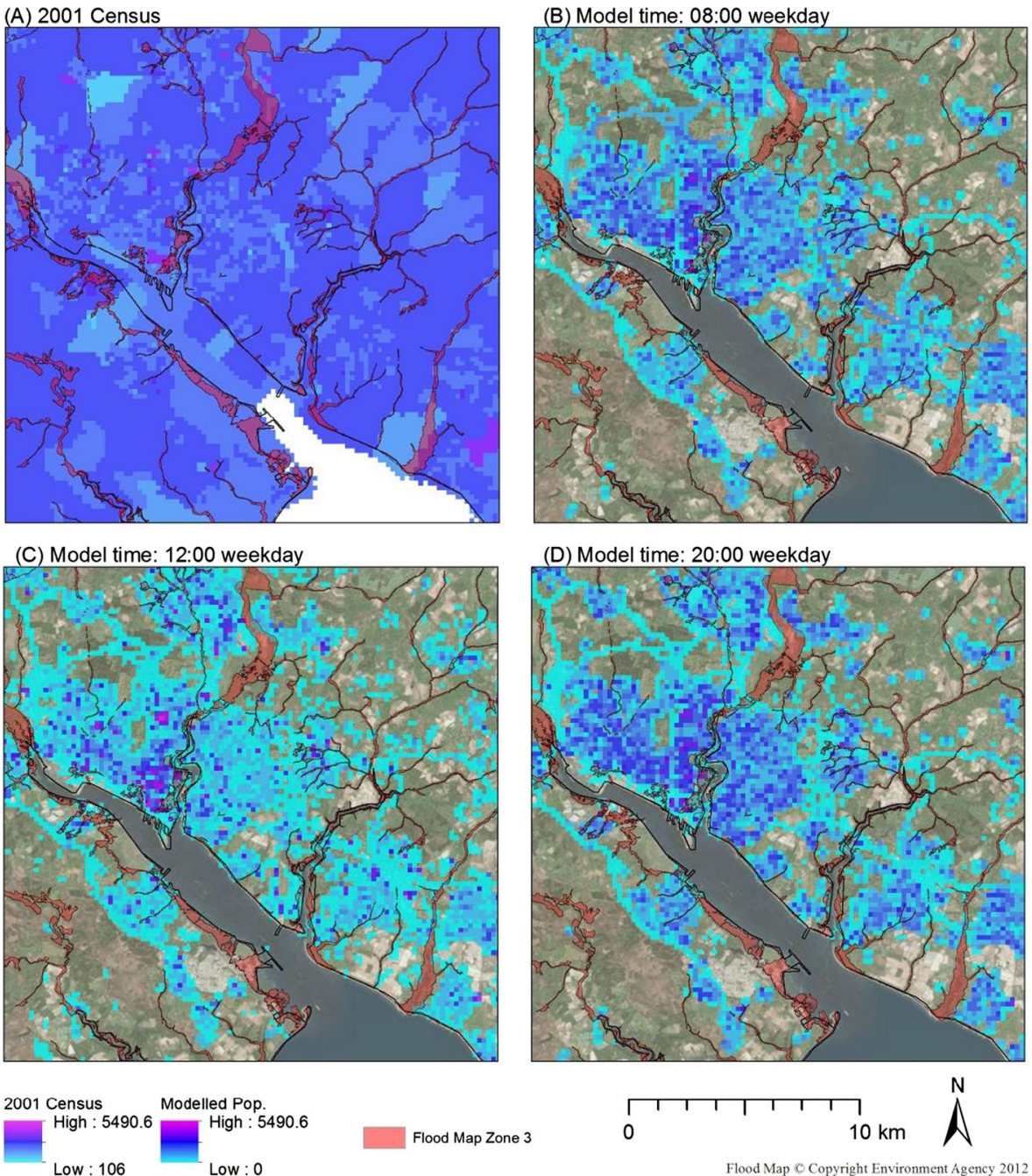

Flood Map Zone 3

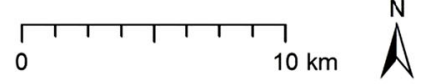
Flood Map $\%$ Copyright Environment Agency 2012
2001 Census Output Area Boundaries 0 Crown copyright 2003
10 Copyright Microsoft Corporation and its data suppliers 2010 Bing Maps Aerial 0 Copyright Microsoft Corporation and its data suppliers 2010

Fig. 5 Rasterised 2001 census output area total population counts (a). Spatio-temporal model outputs showing total population for three time slices, together with Environment Agency flood map data (b to d). All maps at $200 \mathrm{~m}$ resolution for a 'typical' weekday

closely resembles the reciprocal of tidal exposure with a symmetry approximately aligned to typical working hours (09:00-17:00). This is attributable to the concentration of industry and commercial activity in coastal locations compared to large residential areas inland close to major rivers (Itchen and Test). As employees commute to the coastal regions during the day their tidal flood exposure increases; when they return home to residential locations further inland in the evening fluvial flood risk becomes the dominating factor. This spatio-temporal variation contrasts strongly with the static representation of population exposure produced by the traditional census (also shown in Fig. 6), which generally tends to overestimate exposure. 


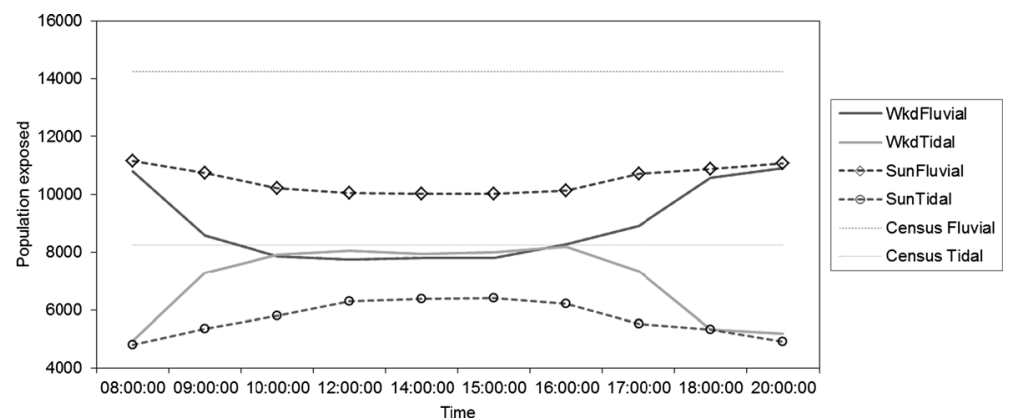

Fig. 6 Estimated total population exposure by time of day for flood map zone three comparing the static census, a modelled 'typical' weekday and a typical Sunday. Where the annual fluvial flood risk is $1 \%$ and tidal $0.5 \%$

Figure 7 indicates the total population exposed to fluvial and tidal flood risk at 12:00 and 20:00, showing the composition by age group. The differences in exposure between tidal and fluvial flooding at different times of day are most notable within the working aged population (16-64). It can also be seen from the heights of the bars that the total population exposed fluctuates over time with tidal exposure at 20:00 being the lowest.

Further analysis of the population engaged in different activities at representative times of 08:00 and 12:00 has been conducted for the working age population (Fig. 8a to c). The figure shows the population in these groups who are travelling in the transportation network (in travel) or at a non-residential destination site (on site). These were selected to demonstrate the utility of the method for analysing the distribution of population during a typical morning commute and middle of working day. At 08:00 (Fig. 8b) it can be seen that the working age population density at non-residential destinations is relatively low, compared to Fig. 8c which reflects the concentration of this subgroup at workplaces and other destinations during the day. As expected, when more people migrate into a hazardous zone, exposure is dramatically increased within this age range during the day. Figure $8 \mathrm{~d}$ shows a large increase in the working age population in both potential exposure to fluvial and tidal flood risk at midday when this population is typically on site at a place of work. The distribution of the university student population has also been examined for the same typical term time weekday (Fig. 9). During the day, the student population is concentrated on the city's two universities and spreads back into the student residential areas during the evening.

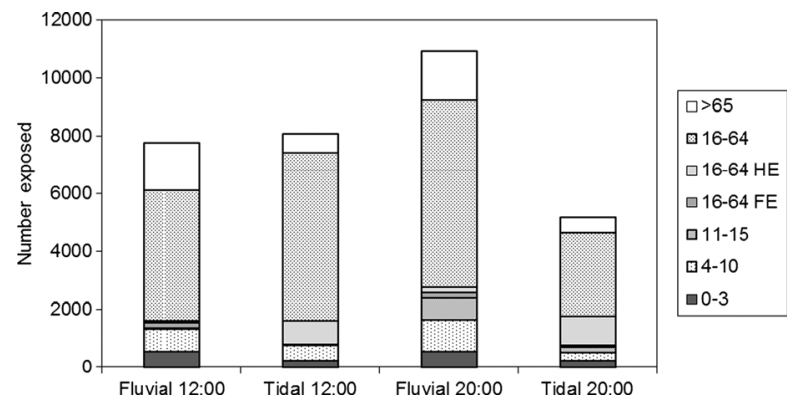

Fig. 7 Age composition of population potentially exposed to fluvial and tidal flooding during the working day (midday) and evening (20:00) HE: Higher Education; FE: Further Education 
The daily variation of the student population that only occurs during term time demonstrates how their potential susceptibility is time dependent (Fig. 6).

The diurnal trends in the modelled data (Fig. 6) might have been predicted, but can be isolated and quantified using the methodology proposed. During 'typical' weekday working hours there is a shift from fluvial to tidal flood risk. It was possible to narrow this change down to the working aged population (Fig. 7). Population exposure was further analysed for representative times of midday and 20:00. This provided insight into two contrasting points in the usual daily cycle. The reversal from tidal to fluvial exposure occurs in the 16-64 working age population. At midday tidal risk is the predominant risk to this population subgroup, however by 20:00 this again becomes fluvial. As the working population returns to primarily residential locations further
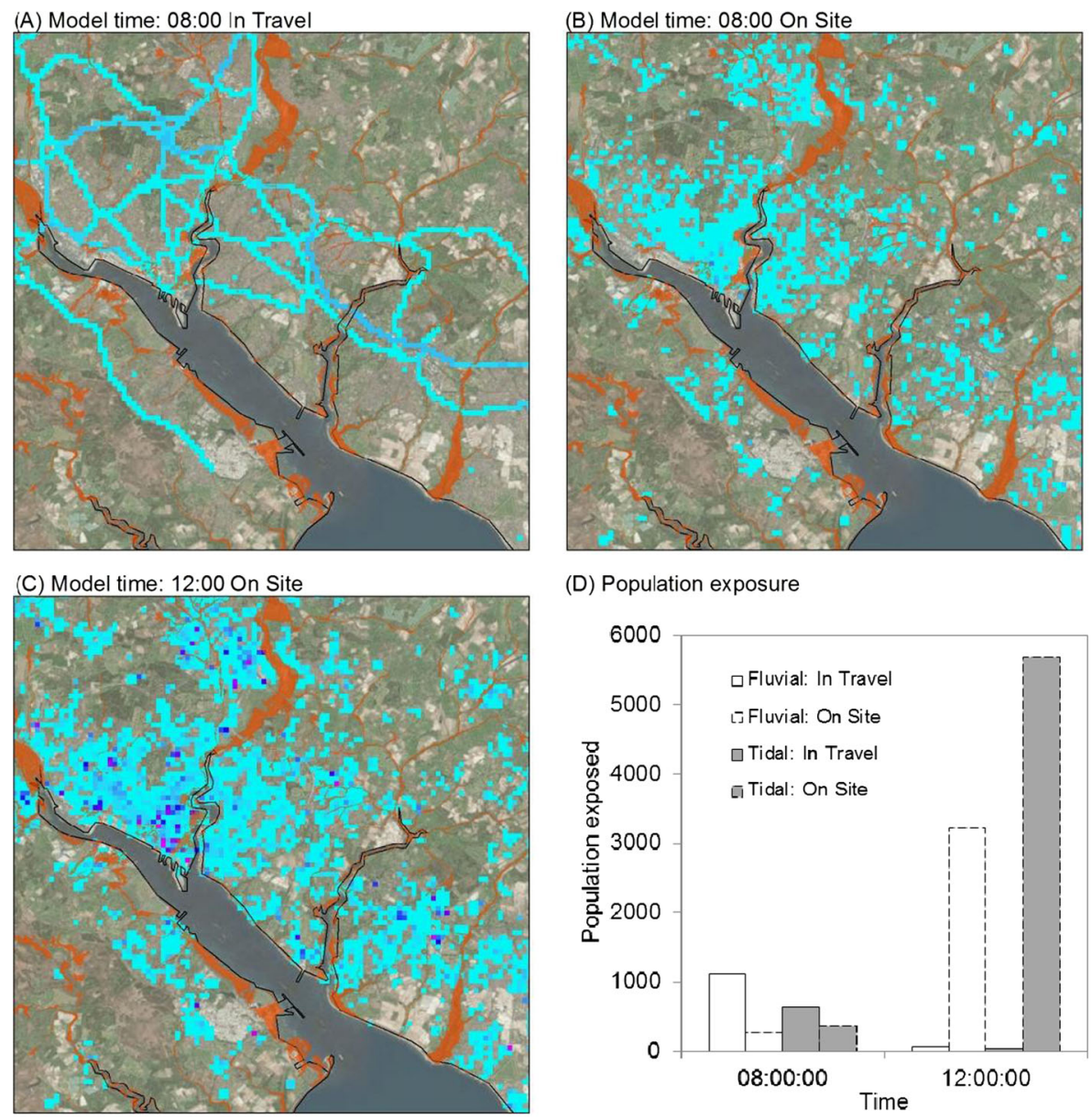

(D) Population exposure

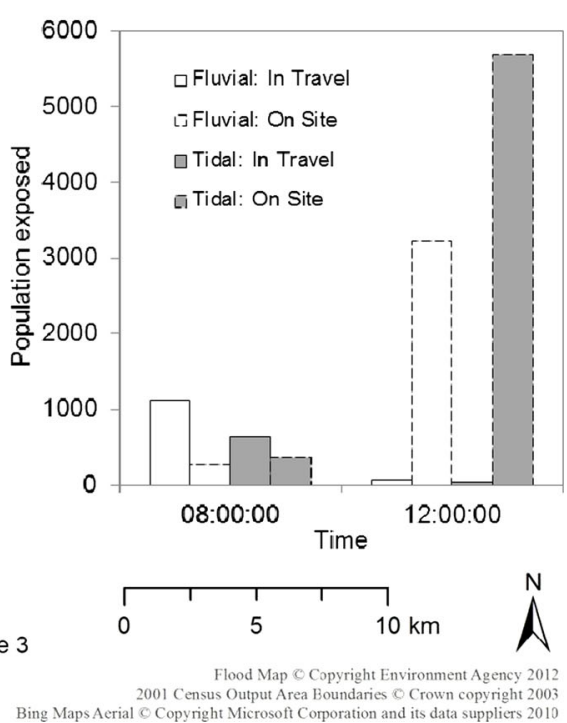

Workingage (16-64) pop. High : 5404.45

Low : 0

Fig. 8 Modelled results for the working aged (16-64) population in travel (a) and on site (b) at 08:00 and at 12:00 (c). The flood risk exposure to the working age population (d) 


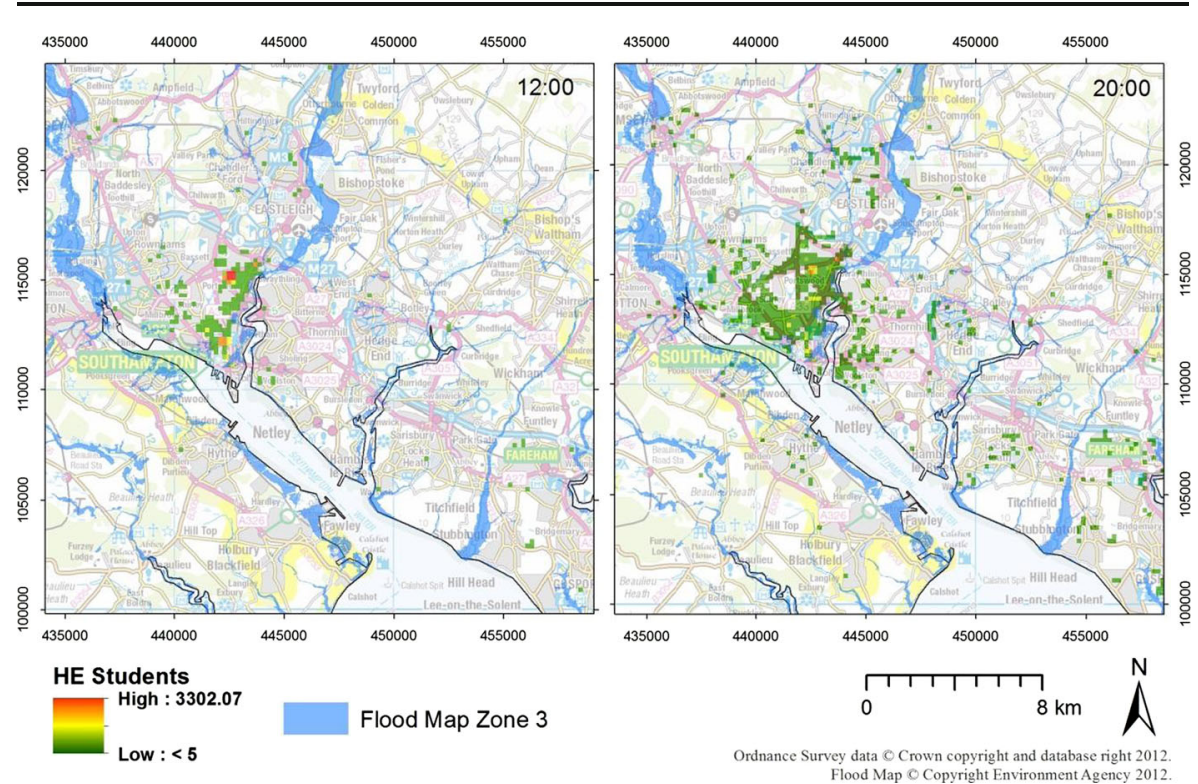

Fig. 9 Modelled representation of the higher education (HE) student population for a typical term time weekday at 12:00 and 20:00

inland, fluvial risk becomes the main factor. It can also be observed that there is a notable tidal flood risk to higher education students throughout the day. While there is not such a large reversal of this trend in the evening it does decrease reflecting the locations of student halls of residence or sites within the institutions. The spread of students in evening residential locations (Fig. 9) shows that a large portion are within the central area of the city with more prominent flood risks. For vulnerability assessment and the purposes of emergency preparedness this technique provides valuable improvements over traditional static hazard maps.

Figure 6 shows that calculating fluvial and tidal population exposure using the 2001 census residential locations tends to overestimate flood exposure, particularly for fluvial flooding in this study area. As well as providing better differentiation of which areas are inhabited or not at specific times the modelled results suggest that large portions of the time-specific population at risk are highly concentrated in specific areas depending on the time of day and age range (e.g. Figs. 5, 8 and 9): the spread and concentration of population at given times is of critical importance to emergency planners for targeting resources and developing plans.

\section{Discussion}

The modelled outputs, even in this relatively simple example, contrast starkly with the coarse, static 'night-time' population density coverage given by the 2001 census OA map. The modelled outputs reveal the ebb and flow in population density at different locations during the working day, including areas which are uninhabited. Despite their widespread use for exposure assessment, such variations in population density are not captured by traditional census maps. The proposed methodology allows the integration 
of additional hazard maps or more sophisticated hazard models in Fig. 1b. Urban areas and large conurbations experience a diverse range of population interactions and fluctuations. While the hazard footprints used in this case study appear static they are in fact based on complex hydrological modelling undertaken by the Environment Agency and their partners. Important trends can be resolved in the static hazard data and the techniques could be equally applied to more dynamic models.

Figure 3 illustrates an example temporal profile for a specific population activity. Acquiring data of sufficient resolution to inform temporal distributions of population for a given activity is one challenge for this approach. In this example, time use data from a large scale nationally representative survey were employed. The assumed constant ratio of customers to retail employees is used as a proxy for store size and resultant footfall in the absence of uniform data coverage. This approach encompasses numerous simplifying assumptions but nevertheless achieves transfer of population into major retail centres following a realistic temporal profile. This can be amended without fundamentally altering the overall modelling approach. In terms of retail activity it would be possible to improve this profile and destination capacities using detailed site specific commercial datasets. Indeed, any or all of the input datasets could be enhanced or updated without fundamentally altering the overall modelling approach.

The temporal characteristics of the natural hazard have not been directly addressed in this case study. Tidal time and height are not accounted for here but vary continuously as part of a predictable pattern. Tidal information indicating a high spring tide under storm surge conditions in the middle of the working day would potentially have a greater effect on some of the population subgroups identified in this study. Such temporally-specific hazard information could be easily implemented to advance the modelling further.

The modelled results provide enhanced assessments of subgroups of the population and their activities. They can be used to simulate peak travel times and populations in transit. This case study confirms that specific age groups are more at risk at different times. The richness of this detail cannot be derived from static census estimates alone, although the availability of accurate census small area statistics remains an important data source. The enhancements seen here come partly from the non-space-filling nature of the gridded model used, but importantly also reflect the continuous temporal redistribution within the course of a day. Alternative spatial models include dasymetric approaches (e.g. Mennis 2003) and other areal interpolation techniques (e.g. Goodchild and Lam 1980; Xie 1995). These all provide means of representing more realistic spatial population distributions compared to the basic census zone approach but none of them provide a method for modelling population in both space and time: the spatiotemporal gridded method adopted in this paper provides one possible solution. While a raster output may not be desired in all situations it does facilitate integration with the raster outputs of flood inundation models. High resolution disaggregated spatiotemporal population counts permit detailed assessment of potential hazard exposure and impact as well as understanding of wider implications. The flood scenarios described in the example study area may not be considered rapid onset events with modern prediction and forecasting tools, but flooding does have the potential to occur rapidly and without prior warning (Murray et al. 2012).

The key contribution of this study has been to test a modelling approach which combines a non-space-filling representation with the ability to store and analyse the temporal redistribution of the population. The methodology provides a mechanism to 
estimate temporary and transient populations not previously accounted for in many flood risk applications.

The Population 24/7 method also provides scope to analyse the vulnerability of entire populations in more detail through the ability to study population subgroups with differing vulnerability characteristics. Vulnerability is a key contributing factor in the development of a hazard: the capacity to estimate vulnerability may inform management choices for groups such as the young or elderly who may require additional support during an emergency situation. The prominence of the student subgroup in the Southampton example serves to illustrate the importance of daily movements by large subgroups and the sensitivity of analysis to other cyclical timescales, in this case educational term dates. The approach followed here also improves the allocation of population subgroups to specific location and activities, such as school age children at school locations during school time. This type of information is of importance when targeting emergency response and health care provision.

Like hazards, the global population is unevenly distributed, often being concentrated on coastlines, along rivers and active seismic or volcanic regions. The size, location and demographic characteristics of a population are all drivers for the impacts of a natural hazard (Cutter 2010). Spatio-temporal population estimates can highlight cyclical patterns in population distribution. These may be on seasonal scales such as tourism, seasonal shoppers or students arriving at a university town during term time. Notable diurnal cycles have also been observed such as children attending school or employees arriving at work. These all have important implications for natural hazard impact assessments. The timing of the manifestation of a natural hazard will affect the population numbers and vulnerability of those exposed.

This approach does not attempt to provide insights into human behaviour in an emergency situation or provide real time information. It essentially describes predictable population redistribution over time. There are many ways in which the data sources and detailed distributional models could be enhanced within the current modelling framework. For the purpose of this simple demonstration a static flood hazard map has been utilised. Integrating this model with dynamic hazard models is a logical further step that would greatly enhance the understanding of spatio-temporal variations in risk to flooding. The approach can be utilised to inform emergency plans for known risks under a range of scenarios and temporal scales and, while it is not possible to know exact future population movements, it allows for the computation of probable distributions.

Validation of this approach and its modelled outputs is difficult. Where data are available and accessible at the required scale, there are some potential routes for validation. Approaches to consider may be the use of geo-referenced social media interactions, mobile telephony data or individual membership and visitor datasets. These suggestions may allow validation based on certain subgroups of the population, specific geographic areas or specific times, but it is not possible to validate all temporal and spatial scales at once. Currently, there is still work to be done on the availability, coverage, and release of such potentially sensitive data. Further evaluation needs to be undertaken of the sensitivity of modelled outputs to variation in input parameters and the production of measures of uncertainty. It is an inherent feature of this modelling approach that it cannot allocate more population to a location (e.g. pupils to a school) than are in fact recorded in the relevant data source. 
The methodology proposed in this paper can be used to estimate population at risk to a given hazard event and can be adapted to a range of spatial and temporal scales. This has the potential to aid policy makers in managing risk such as defining local flood hazard under the EU Flood Directive which meets legislative criteria. The directive's preliminary flood risk assessment stipulates a requirement to assess the potential adverse consequences of future flood events for human health, including the position of populated areas. While this technique may not be appropriate at the micro level because of uncertainties within population movements it does provide richness of information at a regional level to better inform flood risk in populated areas. The main advantage in any technique with temporal variation is to acknowledge that the extents and populations of inhabited areas are not static. A major development of this methodology would be the integration of a spatial interaction model to enhance the catchment areas of destination locations, and the location of populations in the transportation system more broadly.

\section{Conclusion}

This paper demonstrates improvements in the accuracy of estimated population exposure to hazards to be gained via the adoption of an innovative integrated modelling approach which takes explicit account of both space and time. This is of particular importance when assessing population exposure to natural hazards which are themselves subject to continuous spatio-temporal variation. The potential utility of such models in flood risk management has been demonstrated, providing a wealth of detailed data for further analysis which could not be achieved using conventional means of processing key sources such as census data. Pending further dataset development and validation, this technique has direct application to natural hazard scenarios both within the UK and globally. The data structure of the model allows the user to readily refine or supplement the input datasets. Web data mining and the rise of open-source data are likely to make compiling time-referenced population datasets easier, albeit with increased challenges for data interpretation and validation. The results in this paper provide significant opportunities to further refine this methodology for policy makers and emergency planners.

Acknowledgments Funded by the Economic and Social Research Council. The authors gratefully acknowledge the research assistance of Samuel Leung.

Flood Map reproduced with permission (C Copyright/database rights Environment Agency 2012, Licence $3831 / \mathrm{cw}$.

Open Access This article is distributed under the terms of the Creative Commons Attribution License which permits any use, distribution, and reproduction in any medium, provided the original author(s) and the source are credited.

\section{References}

ABP (2013). ABP Southampton Port Information. http://www.southamptonvts.co.uk/Port_Information/. Accessed 22/03/2013.

Alexander, D. (1993). Natural disasters. London: UCL Press. 
Aubrecht, C., Özceylan, D., Steinnocher, K., \& Freire, S. (2012a). Multi-level geospatial modeling of human exposure patterns and vulnerability indicators. Natural Hazards, 1-17 (DOI: 10.1007/s11069-1101210389-11069), doi:10.1007/s11069-012-0389-9.

Aubrecht, C., Steinnocher, K., Köstl, M., Züger, J., \& Loibl, W. (2012b). Long-term spatio-temporal social vulnerability variation considering health-related climate change parameters particularly affecting elderly. Natural Hazards, 1-14, doi:10.1007/s11069-012-0324-0.

Baxter, P. J. (2005). The east coast Big Flood, 31 January-1 February 1953: a summary of the human disaster. Philosophical Transactions of the Royal Society A: Mathematical, Physical and Engineering Sciences, 363(1831), 1293-1312. doi:10.1098/rsta.2005.1569.

Bettess, R. (2005). Flooding in boscastle and north Cornwall, august 2004 (Phase 2 studies report (pp. 170)). Environment Agency: HR Wallingford.

Bhaduri, B., Bright, E., Coleman, P., \& Urban, M. (2007). LandScan USA: a high-resolution geospatial and temporal modeling approach for population distribution and dynamics. GeoJournal, 69(1), 103-117. doi: 10.1007/s10708-007-9105-9.

Burt, S. (2005). Cloudburst upon hendraburnick down: the boscastle storm of 16 august 2004. Weather, 60(8), 219-227. doi:10.1256/wea.26.05.

CIESIN (2013). Gridded Population of the World (GPWv3). http://sedac.ciesin.columbia.edu/data/collection/ gpw-v3/sets/browse. Accessed 18/01/2013.

Cressman, G. P. (1959). An operational objective analysis system. Monthly Weather Review, 87(10), 367-374. doi:10.1175/1520-0493(1959)087<0367:aooas $>2.0$. co;2.

Cutter, S. L. (2010). Social science perspectives on hazards and vulnerability science. In T. Beer (Ed.), Geophysical hazards (pp. 17-30). Netherlands: Springer.

Cutter, S. L., \& Finch, C. (2008). Temporal and spatial changes in social vulnerability to natural hazards. Proceedings of the National Academy of Sciences, 105(7), 2301-2306. doi:10.1073/pnas.0710375105.

DEFRA. (2011). Flood risk management in England. London: National Audit Office, TSO.

DfT (2005). National Transport Model: FORGE The Road Capacity \& Costs Model. http://webarchive. nationalarchives.gov.uk/20110202223628/http://www.dft.gov.uk/pgr/economics/ntm/ etheroadcapacityandcosts3031.pdf. Accessed 18/03/2014.

DfT (2009). Values of Time and Operating Costs: TAG Unit 3.5.6. http:/www.dft.gov.uk/webtag/documents/ archive/1104/unit3.5.6.pdf. Accessed 18/03/2014.

DfT (2013). Great Britain Road Traffic Survey. http://www.dft.gov.uk/traffic-counts/. Accessed 27/03/2013.

Environment Agency (2012). England and Wales Zone 3 Flood Map. http://www.environment-agency.gov.uk/ homeandleisure/37837.aspx. Accessed 22/03/2013.

European Council (2007). Council Directive 2007/60/EC of the European Parliament and of the Council of 23 October 2007 on the assessment and management of flood risks. Official Journal of the European Union L 288/27, 6.11.2007, 27-34.

Fielding, J. (2007). Environmental injustice or just the Lie of the land: an investigation of the socio-economic class of those at risk from flooding in England and Wales. Sociological Research Online, 12(4), 4.

Gevertz, J. (2014). Aberystwyth University evacuates 600 students following extreme weather reports. The Independent 30/01/2014. http://www.independent.co.uk/student/news/aberystwyth-university-evacuates600-students-following-extreme-weather-reports-9097255.html. Accessed 17/03/2014.

Goodchild, M. F., \& Lam, N. S. (1980). A real interpolation: a variant of the traditional spatial problem. GeoProcessing, 1, 297-312.

Hall, J., Sayers, P., \& Dawson, R. (2005). National-scale assessment of current and future flood risk in England and Wales. Natural Hazards, 36(1-2), 147-164. doi:10.1007/s11069-004-4546-7.

Hallegatte, S., Green, C., Nicholls, R., \& Corfee-Morlot, J. (2013). Future flood losses in major coastal cities. Nature Climate Change, 3, 802-806.

Harper, G., \& Mayhew, L. (2012). Applications of population counts based on administrative data at local level. Applied Spatial Analysis and Policy, 5(3), 183-209. doi:10.1007/s12061-011-9062-z.

HESA (2012). All students by HE institution 2011/12. Higher Education Statistics Agency. https://www.hesa. ac.uk/. Accessed 10/07/2014.

Hilhorst, D., \& Bankoff, G. (2008). Introduction: mapping vulnerability. In G. Bankoff, G. Frerks, \& D. Hilhorst (Eds.), Mapping vulnerability: disasters, development and people (pp. 145-158). London: Earthscan.

HM Government. (2010). A strong Britain in an Age of uncertainty: the national security strategy. London: HMSO.

Horsburgh, K., \& Horritt, M. (2006). The Bristol channel floods of 1607 -reconstruction and analysis. Weather, 61(10), 272-277. doi:10.1256/wea.133.05.

Hunter, N. M., Bates, P. D., Neelz, S., Pender, G., Villanueva, I., Wright, N. G., et al. (2008). Benchmarking 2D hydraulic models for urban flooding. Proceedings of the ICE - Water Management, 161(1), 13-30. 
Huppert, H. E., \& Sparks, R. S. J. (2006). Extreme natural hazards: population growth, globalization and environmental change. Philosophical Transactions of the Royal Society A: Mathematical, Physical and Engineering Sciences, 364(1845), 1875-1888. doi:10.1098/rsta.2006.1803.

Ipsos-RSL, \& ONS. (2000). UK time Use survey 2000. Colchester, Essex: UK Data Archive.

King, R., \& Ruiz-Gelices, E. (2003). International student migration and the European 'year Abroad': effects on European identity and subsequent migration behaviour. International Journal of Population Geography, 9(3), 229-252. doi:10.1002/ijpg.280.

Marsh, T. J. (2004). The january 2003 flood on the Thames. Weather, 59(3), 59-62. doi:10.1256/wea.212.03.

Marsh, T. J. (2008). A hydrological overview of the summer 2007 floods in England and Wales. Weather, 63(9), 274-279. doi:10.1002/wea.305.

Martin, D. (1989) Mapping population data from zone centroid locations Transactions of the Institute of British Geographers NS, 14, 90-97.

Martin, D. (1996). Geographic information systems: socioeconomic applications. London: Routledge.

Martin, D. (2011). SurfaceBuilder247: User Guide. http://www.esrc.ac.uk/my-esrc/grants/RES-062-23-1811/ outputs/Read/ece508b5-6438-4e96-99eb-8fd68f1d3b99. Accessed 30/01/2014.

Martin, D., \& Bracken, I. (1993). The integration of socioeconomic and physical resource data for applied land management information systems. Applied Geography, 13(1), 45-53. doi:10.1016/0143-6228(93)90079G.

McGinnigle, J. B. (2002). The 1952 Lynmouth floods revisited. Weather, 57(7), 235-242. doi:10.1256/ 004316502760195894.

McPherson, T. N., \& Brown, M. J. (2004). Estimating daytime and nighttime population distributions in US cities for emergency response activities. Paper presented at the Symposium on Planning, Nowcasting and Forecasting in the Urban Zone, 84th AMS Annual Meeting, Seattle.

Mennis, J. (2003). Generating surface models of population using dasymetric mapping. Professional Geographer, 55(1), 31-42.

Mitchell, J. K. (1999). Natural disasters in the context of megacities. In J. K. Mitchell (Ed.), Crucibles of hazard: mega-cities and disasters in transition (p. 450). Tokyo: United Nations University Press.

Munich Re. (2012). Natural catastrophes 2011. Analyses, assessments, positions. München, Germany: Topics Geo.

Murray, S. J., Smith, A. D., \& Phillips, J. C. (2012). A modified flood severity assessment for enhanced decision-support: application to the Boscastle flood of 2004. Weather and Forecasting, 27(5), 1290-1297. doi:10.1175/waf-d-12-00033.1.

NFDC (2009). Cabinet 06/07/09 Report A: North Solent Shoreline Management Plan. http://www.newforest. gov.uk/committeedocs/cab/CDR05054.pdf. Accessed 22/03/2013.

OJ (2007). Official Journal of the European Union L 288, 6.11.2007, (p. 27-34). Special edition in croatian Chapter 15 Volume 001 p. 186-193.

ONS (2006a). Annual Business Inquiry. Office for National Statistics.

ONS (2006b). National Statistics Postcode Directory Office for National Statistics.

Openshaw, S. (1984). The modifiable a real unit problem. Norwich: Geo Books.

Pitt, M. (2008). The Pitt review: learning lessons from the 2007 floods. London: Cabinet Office.

RMS (2007). 1607 Bristol Channel Floods: 400-year retrospective: Risk Management Solutions Report.

Rowe, D. (2004). Boscastle: 16th august 2004 - the day of the flood. Cornwall, UK.: Truran.

Ruocco, A., Nicholls, R., Haigh, I., \& Wadey, M. (2011). Reconstructing coastal flood occurrence combining sea level and media sources: a case study of the Solent, UK since 1935. Natural Hazards, 59(3), 17731796. doi:10.1007/s11069-011-9868-7.

Schmitt, R. C. (1956). Estimating daytime populations. Journal of the American Institute of Planners, 22(2), 83-85. Tobin, G. A., \& Montz, B. E. (1997). Natural hazards: explanation and integration. New York: The Guilford Press.

United Nations. (2008). World urbanization prospects: the 2007 revision. New York: United Nations, Department of Economic and Social Affairs.

Wadey, M. P., Nicholls, R. J., \& Hutton, C. (2012). Coastal flooding in the Solent: an integrated analysis of defences and inundation. Water, 4(2), 430-459.

WestQuay (2011). Media Pack. http://www.west-quay.co.uk/assets/Documents/Media\%20Pack\%202011.pdf. Accessed 12/10/2012.

Xie, Y. (1995). The overlaid network algorithms for a real interpolation problem. Computers, Environment and Urban Systems, 19(4), 287-306.

Zevenbergen, C., Veerbeek, W., Gersonius, B., \& Van Herk, S. (2008). Challenges in urban flood management: travelling across spatial and temporal scales. Journal of Flood Risk Management, 1(2), 81-88. doi: 10.1111/j.1753-318X.2008.00010.x. 